\title{
Supplement: Quantifying the contributions of riverine vs. oceanic nitrogen to hypoxia in the East China Sea
}

\author{
Fabian Große $^{1,2}$, Katja Fennel ${ }^{1}$, Haiyan Zhang ${ }^{1,3}$, and Arnaud Laurent ${ }^{1}$ \\ ${ }^{1}$ Department of Oceanography, Dalhousie University, Halifax, NS, Canada \\ ${ }^{2}$ Department of Mathematics and Statistics, University of Strathclyde, Glasgow, United Kingdom \\ ${ }^{3}$ School of Marine Science and Technology, Tianjin University, Tianjin, China
}

Correspondence: Fabian Große (fabian.grosse@dal.ca)

\section{S1 Simulated circulation in the East China Sea}

Zhang et al. (same special issue) assessed the skill of the applied ROMS model with respect to the physics based on sea surface temperature and salinity, which provides a ba5 sic validation of the simulated hydrography. However, our study of the contributions of the different nutrient sources on hypoxia also requires a good representation of the general circulation in the East China Sea (ECS). This is particularly important considering the distinct seasonality of the 10 region due to the East Asian monsoon. Furthermore, it is important to evaluate simulated surface and subsurface currents as intrusion from the Kuroshio occur mainly in the subsurface (Zhou et al., 2017a, 2018). Therefore, Fig. S1 shows average ocean current velocities and directions in the sur15 face (0-25 m; panels a, b) and subsurface ocean (25-200 m; panels c, d) during summer (June to August, 'JJA'; panels $\mathrm{a}, \mathrm{c}$ ) and winter (December to February, 'DJF'; panels b, d) 2008-2013. The main branch of the Kuroshio is well reproduced, visible as a band of high current velocities in the sur${ }_{20}$ face and subsurface (Figs. S1a, b). Maximum velocities of up to $1.6 \mathrm{~m} \mathrm{~s}^{-1}$ occur during summer in the surface layers directly east of Taiwan (Fig. S1a). North of Taiwan, summer currents are driven mainly by inflow through Taiwan Strait, indicated by the band of relatively high velocities off the Chi-

${ }_{25}$ nese coast (Figs. S1a, b). At about $27.5^{\circ} \mathrm{N}, 122.5^{\circ} \mathrm{E}$, the current merges with a subsurface intrusion from the Kuroshio branching northeast of Taiwan (Fig. S1b). This current is partly deflected northeastward at $29^{\circ} \mathrm{N}$, which is in agreement with both another model (Bian et al., 2013) and obser30 vations (Zhou et al., 2017b, 2018).

North of $31^{\circ} \mathrm{N}$, the southward Yellow Sea Coastal Current (YSCC) is simulated in summer and winter (Figs. S1a and b, respectively), but it is weaker and reaches less far south in summer. This behavior is within the range of existing modeling studies, which either simulate a consistent northward current (Bian et al., 2013) or a seasonal reversal of the YSCC (Guo et al., 2006). Existing observations are inconclusive on the seasonality of the YSCC (Bian et al., 2013).

The surface inflow through Taiwan Strait is significantly lower in winter than in summer (compare Figs. S1a and c), due to the southwestward flowing East China Sea Coastal Current with velocities of $0.1-0.3 \mathrm{~m} \mathrm{~s}^{-1}$, which is in line with Bian et al. (2013).

The subsurface Kuroshio intrusion northeast of Taiwan is also present in winter (Fig. S1d), but reaches less far north than during summer. A relatively strong westward current (up to $0.4 \mathrm{~m} \mathrm{~s}^{-1}$ ) at $125^{\circ} \mathrm{E}, 31-32^{\circ} \mathrm{N}$ originating from the Kuroshio is simulated in winter in both the surface and the subsurface (Figs. S1c, d). This is in agreement with model results of Guo et al. (2006), despite slightly higher current 50 velocities in our model.

In summary, our model agrees well with existing literature with respect to the seasonality of surface and subsurface currents in the ECS. Thus, it provides a reliable basis for the source-specific nitrogen tracing.

\section{S2 Source-specific gross oxygen consumption in northern and southern region}

Table $\mathrm{S} 1$ provides the values for gross oxygen consumption (GOC), its relative contributions by the different $\mathrm{N}$ sources and total hypoxic areas for the northern and southern regions 60 corresponding to the analyses presented in section 3.3 of the main text. Table $\mathrm{S} 2$ provides the analogous values and wind velocities corresponding to the results presented in section 3.4 of the main text. 

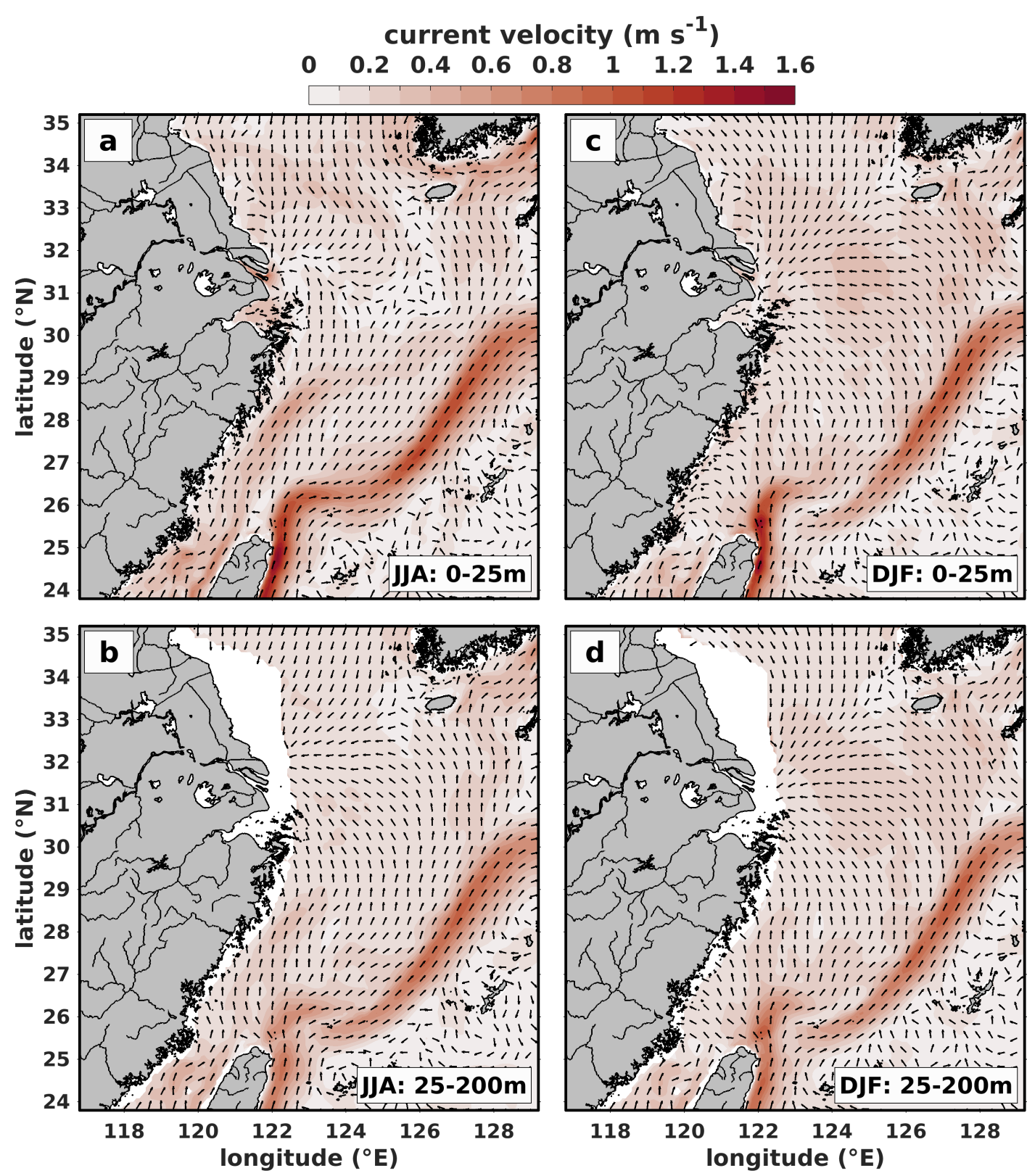

Figure S1. Temporally (2008-2013) and vertically averaged ocean current directions (arrows) and velocities (colors) near the surface (025m; a, c) and in the subsurface ocean (25-200m; b, d) during summer (June-August (JJA); a, b) and winter (December-February (DJF); c, d). Direction vectors are sampled every four grid cells and have the same length. Same color scale for all panels.

\section{S3 Seasonal cycle of freshwater thickness and stratification}

To study the effect of the Changiiang River on stratification, we calculate the freshwater (FW) thickness using the passive 5 dye tracers from the Changjiang River. The FW thickness at a specific location $(x, y, t)$ is defined as (Zhang et al., 2012):

$h_{f w}=\int_{-z_{0}}^{\eta} C_{p} d z$
Here, $\eta$ and $z_{0}$ are the sea surface elevation at $(x, y, t)$ and the reference depth down to which the dye tracer concentration $C_{p}$ attributed to Changjiang River is integrated, respectively. We use $z_{0}=25 \mathrm{~m}$ as the amount of FW in the nearsurface layers is the most relevant for stratification.

We use potential energy anomaly (PEA; Simpson, 1981), a measure for the stability of a water column, to analyze strat- 
Table S1. Average gross oxygen consumption (GOC; in $\mathrm{mmol} \mathrm{O}_{2} \mathrm{~m}^{-2} \mathrm{~d}^{-1}$ ), its source-specific contributions (in \%) and total hypoxic area $\left(A_{H}\right.$; in $10^{3} \mathrm{~km}^{2}$ ) in the northern and southern analysis regions (see Fig. 1, main text) during July to November of the years $2008-2013$ and averaged ( \pm 1 standard deviation) over the entire period. Values for GOC and $A_{H}$ correspond to Fig. 4 in the main text. Yellow Sea contribution is not shown (always $<0.2 \%$ ). Percentage sums greater than $100 \%$ due to rounding.

\begin{tabular}{|c|c|c|c|c|c|c|}
\hline Year & GOC & Changjiang & Other rivers & Kuroshio & Taiwan Strait & $A_{H}$ \\
\hline \multicolumn{7}{|c|}{ northern region } \\
\hline 2008 & 51.6 & 75.0 & 4.2 & 14.8 & 5.9 & 8.0 \\
\hline 2009 & 52.4 & 78.1 & 3.7 & 12.7 & 5.6 & 8.4 \\
\hline 2010 & 52.5 & 78.2 & 4.0 & 12.1 & 5.6 & 14.4 \\
\hline 2011 & 50.9 & 71.2 & 4.6 & 17.2 & 6.9 & 8.4 \\
\hline 2012 & 54.2 & 77.5 & 4.2 & 12.4 & 5.9 & 8.5 \\
\hline 2013 & 51.5 & 63.3 & 3.6 & 22.4 & 10.7 & 0.5 \\
\hline mean & $52.2 \pm 1.2$ & $73.9 \pm 5.4$ & $4.0 \pm 0.3$ & $15.2 \pm 3.7$ & $6.8 \pm 1.8$ & $8.0 \pm 4.4$ \\
\hline \multicolumn{7}{|c|}{ southern region } \\
\hline 2008 & 42.3 & 60.3 & 4.4 & 19.0 & 16.3 & 12.3 \\
\hline 2009 & 41.9 & 61.1 & 4.7 & 17.8 & 16.5 & 10.5 \\
\hline 2010 & 40.0 & 58.4 & 4.9 & 17.9 & 18.7 & 12.0 \\
\hline 2011 & 38.6 & 51.9 & 4.6 & 22.3 & 21.2 & 5.7 \\
\hline 2012 & 41.8 & 60.2 & 5.1 & 17.7 & 17.1 & 6.3 \\
\hline 2013 & 32.4 & 46.9 & 4.2 & 23.2 & 25.6 & 4.6 \\
\hline mean & $39.5 \pm 3.8$ & $56.9 \pm 5.1$ & $4.7 \pm 0.3$ & $19.5 \pm 2.2$ & $18.9 \pm 3.2$ & $8.6 \pm 3.4$ \\
\hline
\end{tabular}

ification:

$\mathrm{PEA}=\frac{1}{D} \int_{-H}^{\eta} g z(\bar{\rho}-\rho) d z$,

with water column depth $D=-H+\eta$, bottom depth $H$, local depth $z$, gravitational acceleration $g$, potential density $\rho$, 5 and vertically averaged potential density $\bar{\rho}$ :

$\bar{\rho}=\frac{1}{D} \int_{-H}^{\eta} \rho d z$.

Density $\rho$ depends on salinity $(S)$, temperature $(T)$ and pressure $(p)$, and is calculated from the simulated fields using the 'Thermodynamic Equation of Seawater' (TEOS-10; Mc${ }_{10}$ Dougall and Barker, 2011):

$\rho=\rho(S, T, p)$.

To analyze the effect of Changjiang River FW on stratification in the highly variable southern hypoxic region (see main text, Fig. 1), we present time series of monthly and spa15 tially averaged FW thicknesses and PEA over water depth $(\mathrm{PEA} / D)$ for that region for the years of the largest (2008) and smallest simulated hypoxic areas (2013) in Fig. S2.

The FW thickness shows a distinct seasonal cycle with low values during July/August, a strong increase in Septem20 ber/October, followed by a decrease through winter and spring. Only in 2013, this pattern is interrupted by a shortterm increase of FW thickness in June. The seasonal cycle of
$\mathrm{PEA} / D$ is less pronounced, and partly opposed to that of FW thickness. PEA/ $D$ tends to increase from January to June, although FW thickness steadily decreases, which likely results from surface warming and an inflow of oceanic water masses in the subsurface (see Fig. S1b) supporting an increase in stratification.

The strong increase in FW thickness during September of both years coincides with an increase in $\mathrm{PEA} / D$, which is particularly pronounced in 2008, the year of the largest hypoxic area. This is caused by both the higher Changjiang River FW discharge compared to 2013 (see main text, Fig. 2) and the anomalously weak winds in September/October 2008 (see Fig. 5), which enable the longer maintenance of ${ }_{35}$ intense stratification. In contrast, the winds are anomalously strong in September 2013, and FW thickness is almost $2 \mathrm{~m}$ less than in 2008 (see Fig. S2b), resulting in only a minor increase in stratification.

\section{References}

Bian, C., Jiang, W., and Greatbatch, R. J.: An exploratory model study of sediment transport sources and deposits in the Bohai Sea, Yellow Sea, and East China Sea, J. Geophys. Res.-Oceans, 118, 5908-5923, https://doi.org/10.1002/2013JC009116, 2013.

Guo, X., Miyazawa, Y., and Yamagata, T.: The Kuroshio onshore 45 intrusion along the shelf break of the East China Sea: The origin of the Tsushima Warm Current, J. Phys. Oceanogr., 36, 22052231, https://doi.org/10.1175/JPO2976.1, 2006.

McDougall, T. J. and Barker, P. M.: Getting started with TEOS10 and the Gibbs Seawater (GSW) oceanographic toolbox, 50 
Table S2. Monthly averaged gross oxygen consumption (GOC; in $\mathrm{mmol} \mathrm{O}_{2} \mathrm{~m}^{-2} \mathrm{~d}^{-1}$ ), relative contributions by different $\mathrm{N}$ sources (in $\%$ ), hypoxic area $\left(A_{H}\right.$; in $\left.10^{3} \mathrm{~km}^{2}\right)$, and meridional wind $\left(v_{10}\right.$; in $\left.\mathrm{m} \mathrm{s}^{-1}\right)$ in the southern region in 2008 and 2013. Values correspond to results shown in Fig. 5 (main text). Yellow Sea contribution not shown (always $<0.2 \%$ ). Percentage sums greater than $100 \%$ due to rounding.

\begin{tabular}{|c|c|c|c|c|c|c|c|}
\hline Month & GOC & Changjiang & Other rivers & Kuroshio & Taiwan Strait & $A_{H}$ & $v_{10}$ \\
\hline \multicolumn{8}{|c|}{2008} \\
\hline 1 & 15.0 & 67.9 & 3.4 & 14.1 & 14.5 & 0.0 & -6.5 \\
\hline 2 & 6.0 & 66.5 & 3.4 & 16.0 & 14.0 & 0.0 & -6.6 \\
\hline 3 & 30.5 & 66.1 & 4.5 & 13.1 & 16.1 & 0.0 & -2.6 \\
\hline 4 & 33.7 & 66.3 & 5.8 & 12.6 & 15.1 & 0.0 & -1.0 \\
\hline 5 & 20.0 & 42.1 & 7.2 & 22.3 & 28.4 & 0.1 & -0.3 \\
\hline 6 & 23.2 & 34.2 & 11.2 & 27.9 & 26.7 & 0.1 & 3.0 \\
\hline 7 & 35.1 & 28.7 & 7.5 & 33.1 & 30.8 & 1.0 & 4.6 \\
\hline 8 & 43.9 & 37.0 & 6.3 & 31.2 & 25.4 & 1.5 & 1.9 \\
\hline 9 & 67.0 & 76.2 & 3.4 & 11.6 & 8.8 & 8.0 & -1.5 \\
\hline 10 & 42.1 & 77.4 & 2.3 & 11.1 & 9.3 & 7.9 & -3.3 \\
\hline 11 & 23.7 & 76.7 & 2.5 & 9.5 & 11.3 & 6.7 & -5.4 \\
\hline 12 & 23.9 & 74.7 & 2.5 & 9.8 & 13.0 & 0.0 & -4.7 \\
\hline mean & $30.4 \pm 15.8$ & $60.0 \pm 19.4$ & $4.9 \pm 2.5$ & $17.8 \pm 9.2$ & $17.2 \pm 8.3$ & $2.1 \pm 3.3$ & $-1.8 \pm 3.7$ \\
\hline \multicolumn{8}{|c|}{2013} \\
\hline 1 & 6.6 & 75.3 & 2.8 & 11.8 & 10.1 & 0.0 & -4.8 \\
\hline 2 & 12.4 & 74.8 & 3.4 & 11.6 & 10.2 & 0.0 & -4.0 \\
\hline 3 & 29.1 & 67.4 & 4.1 & 14.3 & 14.2 & 0.0 & -2.5 \\
\hline 4 & 38.5 & 67.5 & 5.2 & 13.8 & 13.5 & 0.0 & -1.1 \\
\hline 5 & 22.8 & 55.6 & 7.1 & 17.9 & 19.4 & 0.0 & 0.9 \\
\hline 6 & 39.6 & 62.9 & 8.8 & 14.1 & 14.2 & 1.6 & 1.2 \\
\hline 7 & 27.6 & 35.8 & 6.6 & 21.2 & 36.3 & 4.3 & 5.9 \\
\hline 8 & 26.7 & 2.2 & 2.6 & 42.9 & 52.3 & 0.1 & 3.4 \\
\hline 9 & 49.1 & 56.8 & 5.3 & 20.5 & 17.4 & 0.5 & -3.3 \\
\hline 10 & 34.2 & 61.9 & 3.1 & 19.4 & 15.6 & 0.4 & -6.6 \\
\hline 11 & 24.6 & 68.8 & 2.9 & 14.4 & 13.9 & 0.0 & -4.2 \\
\hline 12 & 20.6 & 72.7 & 3.6 & 9.6 & 14.1 & 0.0 & -6.1 \\
\hline mean & $27.7 \pm 11.7$ & $56.8 \pm 19.7$ & $5.0 \pm 2.0$ & $18.4 \pm 8.4$ & $19.9 \pm 12.1$ & $0.6 \pm 1.3$ & $-1.7 \pm 3.9$ \\
\hline
\end{tabular}

Tech. rep., SCOR/IAPSO, http://www.teos-10.org/pubs/gsw/v3_ 04/pdf/Getting_Started.pdf, 2011.

Simpson, J. H.: The shelf-sea fronts: implications of their existence and behaviour, Philos. T. Roy. Soc. A, 302, 531-546, 5 https://doi.org/10.1098/rsta.1981.0181, 1981.

Zhang, H., Fennel, K., Laurent, A., Zhao, L., and Bian, C.: A numerical model study of the main factors contributing to hypoxia and its sub-seasonal to interannual variability off the Changjiang Estuary, Biogeosciences Discussions, same special issue.

${ }_{10}$ Zhang, X., Hetland, R. D., Marta-Almeida, M., and DiMarco, S. F.: A numerical investigation of the Mississippi and Atchafalaya freshwater transport, filling and flushing times on the TexasLouisiana Shelf, J. Geophys. Res.-Oceans, 117, C11 009, https://doi.org/10.1029/2012JC008108, 2012.

${ }_{15}$ Zhou, F., Chai, F., Huang, D., Xue, H., Chen, J., Xiu, P., Xuan, J., Li, J., Zeng, D., Ni, X., and Wang, K.: Investigation of hypoxia off the Changjiang Estuary using a coupled model of ROMS-CoSiNE, Prog. Oceanogr., 159, 237-254, https://doi.org/10.1016/j.pocean.2017.10.008, 2017a.

${ }_{20}$ Zhou, P., Song, X., Yuan, Y., Wang, W., Cao, X., and Yu, Z.: Intrusion pattern of the Kuroshio Subsurface Water onto the East
China Sea continental shelf traced by dissolved inorganic iodine species during the spring and autumn of 2014, Mar. Chem., 196, 24-34, https://doi.org/10.1016/j.marchem.2017.07.006, 2017b.

Zhou, P., Song, X., Yuan, Y., Wang, W., Chi, L., Cao, X., and Yu, 25 Z.: Intrusion of the Kuroshio Subsurface Water in the southern East China Sea and its variation in 2014 and 2015 traced by dissolved inorganic iodine species, Prog. Oceanogr., 165, 287-298, https://doi.org/10.1016/j.pocean.2018.06.011, 2018. 


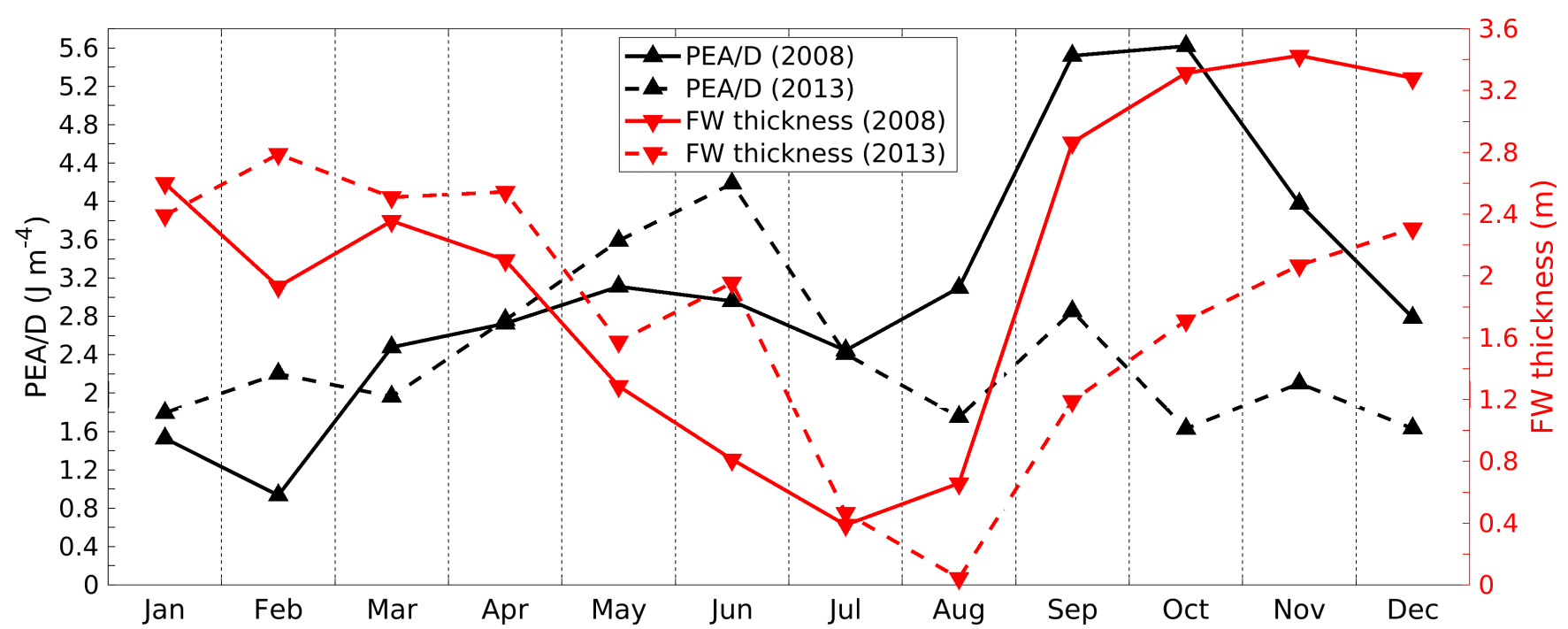

Figure S2. Monthly averaged freshwater (FW) thickness (in upper $25 \mathrm{~m}$ ) and potential energy anomaly over water depth $(\mathrm{PEA} / D)$ in the southern region for the years of the largest (2008) and smallest (2013) hypoxic areas. 